\section{D) Check for updates}

Cite this: Analyst, 2021, 146, 2769

\title{
Electroanalytical overview: the pungency of chile and chilli products determined via the sensing of capsaicinoids
}

\begin{abstract}
Robert D. Crapnell (D) and Craig E. Banks (D)*
When you bite into a chile pepper or eat food containing chile (chilli), one might feel heat, or other associated feelings, some good such as the release of endorphins, and some bad. The heat, or pungency, and related feelings from eating chile peppers are the result of their chemical composition, i.e. the concentrations of capsaicinoids. The major components are capsaicin and dihydrocapsaicin, which occur in chiles in the ratio of $6: 4$. Other capsaicinoids occur in smaller concentrations and are known as the "minor" capsaicinoids. Wilbur L. Scoville in 1912 created an organoleptic test, now known as the Scoville scale, which asked a panel of tasters to state when an increasingly dilute solution of the chile pepper in alcohol no longer burned the mouth. Following the Scoville scale, a plethora of analytical techniques later followed. In this overview, we explore the endeavours directed to the development of electrochemicalbased sensors for the determination of capsaicin and related compounds, starting from their use in hyphenated laboratory set-ups to their modern use as stand-alone electroanalytical sensors. The latter have the advantage of providing a rapid and sensitive methodology that has the potential to be translated in the field; future trends and issues to be overcome are consequently suggested.
\end{abstract}

Received 14th January 2021 Accepted 11th March 2021 DOI: $10.1039 /$ d1an00086a rsc.li/analyst then diluted with sweetened water. $\$$ A panel of five testers would then taste the chile solution and, via serial dilution, continue testing until the pungency was undetectable. If the tester panel could barely detect any heat in a mixture of 1 part of the alcohol solution in 50000 parts of sweetened water, the chile pepper is rated at 50000 Scoville heat units (SHU). This method measures the total capsaicinoid concentration and of course is subjective and depends upon a taster's palate and sensitivity to capsaicinoids, and has clear limitations on throughput and (substantial) serial dilution for hot chile peppers. Note that once exposed repeatedly to capsaicin, the receptors in the mouth that register heat are depleted; this enables eaters to eat hotter and hotter food. However, this would mean every time a person repeated the test their results would indicate a weakening of the same chile. That said, with its limitations, it is a useful approach to effectively benchmark and rank the hotness of chile peppers. Interested readers are directed to ref. 7 for a full biography of Wilbur L. Scoville; a more light hearted recognition honouring Scoville's work are the Scoville ${ }^{\mathrm{TM}}$ awards. ${ }^{8}$
Faculty of Science and Engineering, Manchester Metropolitan University, Chester Street, Manchester M1 5GD, UK. E-mail: c.banks@mmu.ac.uk; Tel: +44 (o)1612471196

$\dagger$ Traditionally, the grain was thought of as the weight of a barleycorn taken from the middle of the ear $(0.0648 \mathrm{~g})$.

\footnotetext{
$¥$ As an aside, note that capsaicin does not dissolve in water, but it does in alcohol and fats, thus whole milk and related food groups will relieve a burning mouth and a glass of water will not. To a far lesser extent, so would alcoholic beverages supply such required relief!
} 

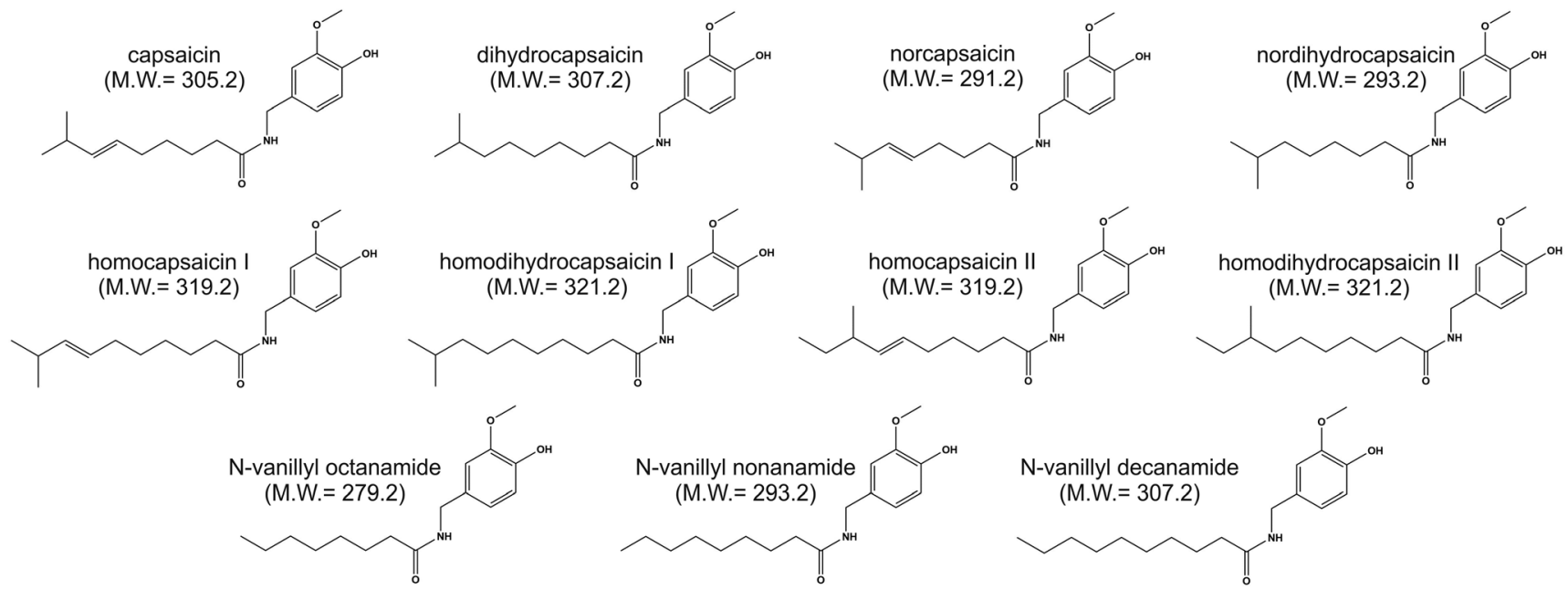

Scheme 1 Overview of the range of capsaicinoids.

The actual pungency of any chile pepper can vary greatly depending on many factors, such as environment, soil, temperature, weather, seed lineage, water and so on. There are five general levels of pungency classified using SHU: non-pungent (0-700 SHU), mildly pungent (700-3000 SHU), moderately pungent (3000-25 000 SHU), highly pungent (25 000-80 000 SHU) and very highly pungent (>80 $000 \mathrm{SHU}) .{ }^{9}$ Interestingly, the high end of the scale can increase significantly from 80000 SHU - The Guinness Book of World Records reports that the hottest chilli pepper is Smokin Ed's 'Carolina Reaper', grown by Ed Currie of PuckerButt Pepper Company (USA), which rates at an average of 1641183 SHU, held at the time of writing this, since $2017 .{ }^{10}$ A word of caution, while chile features in many eating competitions and in programs such as Man vs. Food and others, a man was hospitalised after attempting to eat one Carolina Reaper during a chile pepper eating competition in the USA. ${ }^{11}$ This person developed intense neck and head pain including thunderclap headaches with several arteries constricting, and was diagnosed with reversible cerebral vasoconstriction syndrome; the first recorded time this has been diagnosed after eating chile peppers. ${ }^{11}$ The impact of Capsicum and chile peppers is so great that there is an institute established at New Mexico State University, USA, The Chile Pepper Institute.§ Established in 1992, the institute is the only international, non-profit organization devoted to education

\footnotetext{
§Note that the institute is spelt "chile" rather than "chilli". On their website (https://cpi.nmsu.edu/), which this information is taken from, they inform one that the spelling of the word 'chile' has a long and varied history. Chile comes from the term chilli that comes from the Aztec, Nahuatl language. In their FAQs: they state that, according to Jean Andrews, the Spanish spelling was later changed to chile by Spanish-speaking Mexicans and chili in the United States. We note that at the CPI, they prefer the term chile, which refers to the plant or fruit from the plant while the term chili refers to a culinary dish, consisting of meat, beans, tomatoes and chile powder. We shall use this terminology throughout this overview. Further note that the American English spelling is "chili" while the British English is "chilli".
}

and research related to Capsicum or chile peppers and hosts the world's foremost research-based resource centre for chile pepper information.

In addition to being the main component of chile peppers, capsaicin is reported to possess chemopreventive, antioxidant, anti-bacterial, anti-inflammatory and hypolipidemic effects. ${ }^{12-17}$ Consequently, capsaicin finds use in a range of pharmaceuticals, drug delivery and medical applications such as inclusion in topical creams, liquids and patch preparations for chronic pain syndromes, dietary supplements to tackle obesity and defensive sprays. ${ }^{18-23}$ As such, there is an analytical interest to measure capsaicinoids in a wide range of samples. That said, the majority, if not all, have appeared to have been explored for the sensing of capsaicinoids in chile peppers and chilli products; it is this that we next explore.

\section{Measuring the heat of chiles and related chilli samples}

As described above, the Scoville Organoleptic Test pioneered the way to determine the pungency of chiles. This has now been superseded with the development and application of quantitative analytical approaches. The American Spice Trade Association (ASTA) advocates for the use of high performance liquid chromatography with ultraviolet detection (HPLC-UV) for use in Scoville testing; ${ }^{24}$ see also the Journal of the Association of Official Agricultural Chemists (AOAC) which has also adopted this. ${ }^{24,25}$

Sticher and co-workers appear to have been the first to report the use of HPLC-UV for the quantitative determination of capsaicin, dihydrocapsaicin, nordihydrocapsaicin and homodihydrocapsaicin in natural capsaicinoid mixtures of Capsicum fruits in $1978 .{ }^{26}$ Woodbury ${ }^{27}$ was the first to develop HPLC with spectrofluorescence to determine capsaicin in a range of chile samples (paprikas, chile peppers, and red 
peppers). This methodology was found to be sensitive to $2 \mathrm{ppm}(\sim 32 \mathrm{SHU})$ depending on the pungency level, and it was possible to analyse 20-50 samples in 8 hours. Both methods $^{26,27}$ provide substantial improvements over the Scoville Organoleptic Test. To convert from analytical units, such as ppm capsaicin, to SHU, multiply by 16 , because pure capsaicin measures 16 million Scoville units (an older convention multiplied by 15 but the former should be used). Woodbury, ${ }^{27}$ importantly, was the first to demonstrate a good correlation (coefficient of 0.98) between the concentration determined byHPLC method with that determined organoleptically. ${ }^{27}$ These analytical approaches have of course been naturally extended to a range of other analytical techniques such as ultra-fast liquid chromatography, ${ }^{28}$ gas chromatography-mass spectrometry, ${ }^{29,30}$ liquid chromatography-mass spectrometry, ${ }^{31}$ and liquid chromatography-electrospray ionization/time-offlight mass spectrometry ${ }^{2}$ to name just a few. As noted above, the SHU of a chile pepper can greatly vary due to external environmental conditions, meaning that the SHU value of a chile pepper can vary between a crop and a plant. Hence, rapid analytical approaches are required to provide accurate SHU values. We note that da Silva Antonio and co-workers have elegantly reviewed the evolution of analytical methods for capsaicinoid analysis, providing a summary of the pros and cons of the various approaches. ${ }^{32}$ In this review, we focus predominantly on electrochemical-based sensors due to their rapid, accurate analysis and portability clearly making them, by far, the best option with potential to provide an in-the-field sensing approach for the pungency determination (SHU) of chile and chilli products; therefore this is the sole focus of this overview.

\section{Hyphenated electrochemical approaches}

Table 1 charts the history of the development of electrochemical approaches for the sensing of capsaicinoids and gives an overview of the various exciting approaches employed. Table 1 presents hyphenated techniques, listed in order of publication, followed by non-hyphenated techniques right up to the present day, at the time of writing this review.

The electrochemical detection of capsaicinoids can be traced back to the robust approach of using HPLC with electrochemical detection (HPLC-EC) as initially reported by Kawada and co-workers. ${ }^{33}$ Using an electrochemical detector with a glassy carbon electrode, the authors explored the effect of current (analytical signal) upon the applied electrochemical potential from $+0.5 \mathrm{~V}$ to $+0.9 \mathrm{~V}(v s$. $\mathrm{Ag} / \mathrm{Ag} \mathrm{Cl})$ for the electrochemical oxidation of capsaicin and dihydrocapsaicin at $\mathrm{pH}$ 5.0. A tentative electrochemical oxidation mechanism was suggested involving the loss of $\mathrm{CH}_{3} \mathrm{OH}$ and 2 protons and 2 electrons. ${ }^{33}$ A potential of $+0.75 \mathrm{~V}$ (vs. Ag/ $\mathrm{AgCl}$ ) was chosen as the optimal oxidation potential as a compromise between maximum current response and minimum background current. The detection limits for both capsaicin and dihydrocapsaicin were reported to be $12 \mathrm{pg}$ (39 fmol) and the biological half-life of capsaicin in a rat was investigated. This paper is pivotal as it demonstrates the basis of using electrochemistry as an analytical approach towards the detection of capsaicinoids. Khaled and coworkers $^{34}$ applied micellar electrokinetic capillary chromatography with carbon microelectrodes for the optimised separation of capsaicin and dihydrocapsaicin (as well as homovanillic acid and hydroquinone) at $\mathrm{pH} 6.2$ with femtomolar levels readily detectable. Buratti et $a .^{35}$ reported the use of a flow injection system with an electrochemical detector utilising a glassy carbon working electrode operating amperometrically (potential: $+0.5 \mathrm{~V}$ vs. $\mathrm{Ag} / \mathrm{Ag} \mathrm{Cl}$ ) and determined capsaicin in red, yellow and green bell peppers. The authors noted that up to 60 samples per hour could be analysed, suggesting the direct, rapid and reliable monitoring of capsaicin that makes the flow system an attractive alternative over other reported methods. ${ }^{35}$

Building upon the work on HPLC-EC, flow injection analysis (FIA) with electrochemical detection has been explored for the sensing of capsaicinoids (see Table 1). There are many advantages of FIA over HPLC (see ref. 36 for a full overview) but, predominantly, it has the aim of analysing the maximum number of samples using the minimum amount of time, reagent and sample solution, whilst maintaining a low cost with a high reproducibility. ${ }^{36}$ In terms of the advantages of electroanalysis using FIA, the transport of samples to the detector is fast (convective mass transport) and as such the contact time between the sample and the electrode is reduced, potentially minimising any (detrimental) adsorption effects. ${ }^{37,38}$ Dejmkova et al. $^{39}$ reported the use of flow injection analysis with amperometric dual electrochemical detection (FIA-DED) using a thin layer cell and glassy carbon working electrodes for the simultaneous sensing of capsaicin and dihydrocapsaicin. The operating potentials were explored and optimised with the study comparing FIA-DED with HPLC-DED for 23 samples of chile peppers ranging from mild to very pungent. The authors reported that for small capsaicinoid contents, even HPLC-DED determination did not provide satisfactory results, as its standard deviation was comparable to the measurement value. ${ }^{39}$ As shown in Fig. 1A, the authors examined the correlation between HPLC-DED and FIA-DED results where a tight correlation was observed, but noted that the value of the intercept suggests the tendency to overestimate the real SHU values, ${ }^{39}$ especially at low SHU levels. The authors reported that FIA-DED offers accurate results, as validated by HPLC-DED, for pepper samples of pungencies over approx. $50000 \mathrm{SHU}$, i.e. medium to high level of capsaicinoids. ${ }^{39}$ Clearly, impurities (both electroactive and non-electroactive) in the sample matrix contribute, which is likely to be overcome at high SHU levels due to more sample dilution being required. More rigorous sample pre-treatment will be required to provide accurate results at low SHU levels (i.e. below 50000 SHU). 
Table 1 An overview of the various electrochemical approaches reported for the detection of capsaicinoids

\begin{tabular}{|c|c|c|c|c|c|c|}
\hline Electrode & Method of detection & Analyte & Linear range & $\begin{array}{l}\text { Limit of } \\
\text { detection }\end{array}$ & Sample medium & Ref. \\
\hline GC & $\begin{array}{l}\text { HPLC-EC }(+750 \mathrm{mV} v s . \\
\mathrm{Ag} / \mathrm{AgCl})\end{array}$ & $\begin{array}{l}\text { Capsaicin, } \\
\text { dihydrocapsaicin* }\end{array}$ & $0.25-20 \mathrm{ng}$ & $\begin{array}{l}12 \mathrm{pg} \\
(39 \mathrm{fmol})\end{array}$ & Rat plasma & 33 \\
\hline $\begin{array}{l}\text { Carbon electrode } \\
(33 \mu \mathrm{m} \text { and } 10 \mu \mathrm{m} \\
\text { diameter) }\end{array}$ & $\begin{array}{l}\text { MECC-UV/EC }(+0.9 \mathrm{~V} \\
\text { vs. } \mathrm{Ag} / \mathrm{AgCl})\end{array}$ & Capsaicin dihydrocapsaicin* & ND & $\begin{array}{l}163^{1} \& 82^{1} \\
\text { femtomoles }\end{array}$ & ND & 34 \\
\hline GC & $\begin{array}{l}\text { FI-EC }(+0.5 \mathrm{~V} v s . \mathrm{Ag} / \\
\mathrm{AgCl})\end{array}$ & Capsaicin & ND & ND & Red, yellow and green bell pepper & 35 \\
\hline $\begin{array}{l}\text { Carbon paste } \\
(2.5 \mathrm{~mm} \text { diameter })\end{array}$ & $\begin{array}{l}\text { HPLC-EC (+750 mV vs. } \\
\text { Ag/AgCl) }\end{array}$ & Capsaicin & $\begin{array}{l}31.3-500 \mu \mathrm{g} \\
\mathrm{mL}^{-1}\end{array}$ & $305 \mathrm{ng} \mathrm{mL}^{-1}$ & $\begin{array}{l}\text { Takanotsume; Cecei Fellallo; } \\
\text { Novoselska kapie; Bogyiszloi } \\
\text { Vastaghusu; Jubila }\end{array}$ & 61 \\
\hline Porous carbon & $\begin{array}{l}\text { LC with coulometric } \\
\text { detection }\end{array}$ & $\begin{array}{l}\text { Capsaicin, dihydrocapsaicin } \\
\text { nordihydrocapsaicin* }\end{array}$ & $0.05-100 \mathrm{ng}$ & $10 \mathrm{pg}$ & $\begin{array}{l}\text { Red pepper powder, green, blue } \\
\text { and red pepper, habanero, } \\
\text { bibinba, chillsouce, karamiso, } \\
\text { toubanjan, Tabasco }\end{array}$ & 79 \\
\hline Graphite & $\begin{array}{l}\text { HPLC-ECD }(+450 \mathrm{mV} \\
\text { vs. Pd) }\end{array}$ & $\begin{array}{l}\text { Capsaicin, } \\
\text { dihydrocapsaicin, } \\
\text { nordihydrocapsaicin, } \\
\text { homocapsaicin* }\end{array}$ & ND & ND & $\begin{array}{l}\text { Immature (green), and mature } \\
\text { (orange) chile peppers }\end{array}$ & 80 \\
\hline GC & $\begin{array}{l}\text { FI dual electrode }(+1.0 \\
\mathrm{V} / 0.0 \mathrm{~V} v s . \mathrm{Ag} / \mathrm{AgCl})\end{array}$ & $\begin{array}{l}\text { Capsaicin, } \\
\text { dihydrocapsaicin* }\end{array}$ & $1-200 \mu \mathrm{M}$ & $1.5 \mu \mathrm{M}^{3}$ & 23 chile peppers analysed & 39 \\
\hline $\begin{array}{l}\text { MWCNT-BPPG } \\
\text { electrode }\end{array}$ & AdsSV & Capsaicin & $\begin{array}{l}0.5-15 \mu \mathrm{M} \& \\
15-60 \mu \mathrm{M}\end{array}$ & $0.31 \mu \mathrm{M}$ & $\begin{array}{l}\text { Tabasco green pepper sauce, } \\
\text { Tabasco pepper sauce, Tabasco } \\
\text { habanero sauce, Da' Bomb } \\
\text { Ground Zero, Blair's } 2 \text { AM } \\
\text { Reserve, Mad Dog's Revenge }\end{array}$ & 40 \\
\hline MWCNT-SPE & AdsSV & Capsaicin & $0.5-35 \mu \mathrm{M}$ & $0.45 \mu \mathrm{M}$ & $\begin{array}{l}\text { Tabasco habanero, Mad Dog's } \\
\text { Revenge }\end{array}$ & 40 \\
\hline BDD & AdsSV & Capsaicin & $0.16-20 \mu \mathrm{M}$ & $0.034 \mu \mathrm{M}$ & $\begin{array}{l}\text { Red pepper flakes, hot pepper } \\
\text { paste }\end{array}$ & 56 \\
\hline $\mathrm{NH}_{2}$-FMS-CPE & LSV & Capsaicin & $0.04-0.40 \mu \mathrm{M}$ & $0.02 \mu \mathrm{M}$ & Chile peppers & 81 \\
\hline SWCNT-SPES & $\mathrm{CV}$ & Capsaicin & $0-15 \mu \mathrm{M}$ & $0.91 \mu \mathrm{M}$ & $\begin{array}{l}\text { Habanero peppers, scotch bonnet } \\
\text { peppers, Dutch chile, Tabasco } \\
\text { sauce }\end{array}$ & 41 \\
\hline $\begin{array}{l}\text { Pencil graphite } \\
\text { electrode }\end{array}$ & AdsSV & $\begin{array}{l}\text { Capsaicin } \\
\text { Dihydrocapsaicin }\end{array}$ & $\begin{array}{l}16-320 \mathrm{nM} \\
3.3-330 \mathrm{nM}\end{array}$ & $\begin{array}{l}3.7 \mathrm{nM} \\
0.9 \mathrm{nM}\end{array}$ & Red pepper and Isot pepper flakes & 69 \\
\hline SWCNT-SPES & $\mathrm{CV}$ & Capsaicin & $5-50 \mu \mathrm{M}$ & $0.9 \mu \mathrm{M}$ & ND & 43 \\
\hline HRP/Fc/pHEMA-SPE & Amperometric & Capsaicin & $2.5-99.0 \mu \mathrm{M}$ & $1.94 \mu \mathrm{M}$ & Chile peppers & 74 \\
\hline GC & $\mathrm{CV}$ & Capsaicin & $53-1060 \mu \mathrm{M}$ & $6.4 \mu \mathrm{M}$ & Black pepper & 82 \\
\hline Au NP MWCNT-GC & DPV & Capsaicin & $0.15-35.0 \mu \mathrm{M}$ & $0.3 \mu \mathrm{M}$ & Chile peppers & 44 \\
\hline $\begin{array}{l}\text { Mesoporous cellular } \\
\text { foams }\end{array}$ & DPV & Capsaicin & $0.76-11.65 \mu \mathrm{M}$ & $0.08 \mu \mathrm{M}$ & $\begin{array}{l}\text { Chile pepper, cayenne pepper, bell } \\
\text { pepper }\end{array}$ & 73 \\
\hline B2-SWCNT-SPEs & $\mathrm{CV}$ & Capsaicin & $25-50 \mu \mathrm{M}$ & $0.18 \mu \mathrm{M}$ & ND & 42 \\
\hline GC & $\mathrm{CV}$ & Capsaicin & $0.1-10 \mathrm{mM}$ & ND & $\begin{array}{l}\text { Bird's eye chillies, Ultra Death } \\
\text { Chilli sauce }\end{array}$ & 64 \\
\hline PIGE $^{2}$ & SWV & Capsaicin & ND & ND & $\begin{array}{l}\text { Bhut Jolokia, Red Savina, Fatalli, } \\
\text { Habanero Orange, Carolina } \\
\text { Cayenne, Cayenne, Jalapeño, } \\
\text { Ancho and Hungarian peppers }\end{array}$ & 59 \\
\hline $\begin{array}{l}\text { Graphite pencil } \\
\text { electrodes }\end{array}$ & $\mathrm{CV}$ & Capsaicin & $0.1-100 \mu \mathrm{M}$ & $100 \mathrm{nM}$ & Chili powder & 83 \\
\hline $\begin{array}{l}\text { Graphene-titania- } \\
\text { Nafion }^{\mathrm{TM}} \text { GC }\end{array}$ & LSV & Capsaicin & $0.03-10 \mu \mathrm{M}$ & $8.6 \mathrm{nM}$ & $\begin{array}{l}\text { Chungyang pepper, red pepper } \\
\text { flakes }\end{array}$ & 55 \\
\hline GC & SWV & Capsaicin & ND & ND & $\begin{array}{l}\text { Vezena luta, feferona, bombona, } \\
\text { aiseff f1, dzinki, hybrid } 13515 \text {, } \\
\text { piran, kurtovska kapija chili } \\
\text { peppers }\end{array}$ & 84 \\
\hline $\begin{array}{l}\text { PAL/Nafion }{ }^{\mathrm{TM}} / \\
\text { MWCNTs/Pt }\end{array}$ & DPV & Capsaicin & $20-100 \mu \mathrm{M}$ & $0.6 \mathrm{nM}$ & Chile peppers & 45 \\
\hline RuNP-CNTs-GC & SWV & Capsaicin & $10-410 \mathrm{nM}$ & $2.5 \mathrm{nM}$ & $\begin{array}{l}\text { Isot, Urfa red pepper paste, Antep } \\
\text { red pepper paste, Hatay red } \\
\text { pepper paste }\end{array}$ & 46 \\
\hline $\mathrm{Ag} / \mathrm{Ag}_{2} \mathrm{O}-\mathrm{PSS}-\mathrm{rGO} \mathrm{SPE}$ & DPV & Capsaicin & $1.0-60 \mu \mathrm{M}$ & $0.40 \mu \mathrm{M}$ & $\begin{array}{l}\text { Red pepper, green pepper, } \\
\text { Capsicum frutescens }\end{array}$ & 51 \\
\hline PSS-Grp-SPE & DPV & Capsaicin & $0.3-70 \mu \mathrm{M}$ & $0.1 \mu \mathrm{M}$ & Pod pepper, paprika & 85 \\
\hline PANI-Pt electrode & Amperometry & Capsaicin & $34-215 \mu \mathrm{M}$ & $0.8 \mu \mathrm{M}$ & ND & 86 \\
\hline HRP-NG-SPEs & Chronoamperometry & Capsaicin & $0.75-24.94 \mu \mathrm{M}$ & $0.39 \mu \mathrm{M}$ & Chili fruit sample & 63 \\
\hline Unmodified BPPG & AdsSV & Capsaicin & $0.5-10 \mu \mathrm{M}$ & $0.24 \mu \mathrm{M}$ & ND & 47 \\
\hline
\end{tabular}


Table 1 (Contd.)

\begin{tabular}{|c|c|c|c|c|c|c|}
\hline Electrode & Method of detection & Analyte & Linear range & $\begin{array}{l}\text { Limit of } \\
\text { detection }\end{array}$ & Sample medium & Ref. \\
\hline $\begin{array}{l}\text { Drop-casted } \\
\text { MWCNT-BPPG } \\
\text { electrode }\end{array}$ & AdssV & Capsaicin & $0.5-60 \mu \mathrm{M}$ & $0.17 \mu \mathrm{M}$ & ND & 47 \\
\hline $\begin{array}{l}\text { Drop-casted CB-BPPG } \\
\text { electrode }\end{array}$ & AdsSV & Capsaicin & $0.5-40 \mu \mathrm{M}$ & $0.19 \mu \mathrm{M}$ & ND & 47 \\
\hline $\begin{array}{l}\text { Drop-casted } \\
\text { GNP-BPPG electrode }\end{array}$ & AdssV & Capsaicin & ND & ND & ND & 47 \\
\hline Carbon SPEs & AdsSV & Capsaicin & $0.5-30 \mu \mathrm{M}$ & $0.20 \mu \mathrm{M}$ & ND & 47 \\
\hline MWCNTS-SPEs & AdsSV & Capsaicin & $0.5-20 \mu \mathrm{M}$ & $0.41 \mu \mathrm{M}$ & ND & 47 \\
\hline $\begin{array}{l}\text { Carbon paste } \\
\text { electrode }\end{array}$ & AdsSV & Capsaicin & $0.5-50 \mu \mathrm{M}$ & $0.40 \mu \mathrm{M}$ & ND & 47 \\
\hline $\begin{array}{l}\text { MnSe NP modified } \\
\text { GC }\end{array}$ & DPV & Capsaicin & $5-128 \mu \mathrm{M}$ & $0.05 \mu \mathrm{M}$ & Black pepper & 87 \\
\hline CD-CPE & SWV & $\begin{array}{l}\text { Capsaicin } \\
\text { Dihydrocapsaicin }\end{array}$ & $\begin{array}{l}1.3-9.3 \mu \mathrm{M} \\
0.69-6.7 \mu \mathrm{M}\end{array}$ & $\begin{array}{l}0.21 \mu \mathrm{M} \\
0.30 \mu \mathrm{M}\end{array}$ & Tabasco sauce & 71 \\
\hline EDI-SPEs & LSV & Capsaicin & $5-100 \mu \mathrm{M}$ & $2.77 \mu \mathrm{M}$ & Tabasco sauce & 88 \\
\hline N-MC GC & LSV & Capsaicin & $1-10 \mu \mathrm{M}$ & $0.46 \mu \mathrm{M}$ & $\begin{array}{l}\text { Bird's eye red chili, bird's eye } \\
\text { green chili, green chili, red chili, } \\
\text { sweet green pepper, sweet red } \\
\text { pepper, sweet orange pepper, } \\
\text { sweet dark green pepper }\end{array}$ & 68 \\
\hline $\begin{array}{l}\mathrm{Y}_{2} \mathrm{O}_{3} \text { modified graph- } \\
\text { ite paste electrode }\end{array}$ & DPV & Capsaicin & $1-80 \mu \mathrm{M}$ & ND & ND & 89 \\
\hline $\begin{array}{l}\text { IL-graphene- } \\
\text { Nafion }{ }^{\text {TM-GC }}\end{array}$ & LSV & Capsaicin & $0.03-10 \mu \mathrm{M}$ & $3.2 \mathrm{nM}$ & Chungyang peppers & 53 \\
\hline PGA/MWCNT/GC & DPV & $\begin{array}{l}\text { Capsaicin } \\
\text { Dihydrocapsaicin } \\
\text { Nonivamide }\end{array}$ & $\begin{array}{l}0.01-1.0 \mu \mathrm{M} \\
0.025-0.75 \mu \mathrm{M} \\
0.05-5.0 \mu \mathrm{M}\end{array}$ & $\begin{array}{l}2.9 \mathrm{nM} \\
539 \mathrm{nM} \\
6.1 \mathrm{nM}\end{array}$ & Red hot peppers & 48 \\
\hline PDDA-rGO/Pd/GC & $\mathrm{CV}$ & Capsaicin & $0.32-64 \mu \mathrm{M}$ & $0.10 \mu \mathrm{M}$ & Chile peppers & 67 \\
\hline SPE & DPV & Capsaicin & $0.16-16.37 \mu \mathrm{M}$ & $0.05 \mu \mathrm{M}$ & $\begin{array}{l}\text { Meiren chilli pepper, Chaotian } \\
\text { green chilli pepper, Chaotian red } \\
\text { chilli pepper, Xiaomi green chilli } \\
\text { pepper, Xiaomi red chilli pepper }\end{array}$ & 70 \\
\hline SPE & CCSWV & Capsaicin & $1.98-5000 \mu \mathrm{M}$ & $1.98 \mu \mathrm{M}$ & $\begin{array}{l}\text { Tabasco Chipotle, Tabasco Pepper } \\
\text { and Tabasco Habanero }\end{array}$ & 78 \\
\hline $\begin{array}{l}\text { Paper-based screen- } \\
\text { printed bulk } \\
\text { modified with carbon } \\
\text { black }\end{array}$ & DPV & Capsaicin & $0.08-6 \mu \mathrm{M}$ & $0.03 \mu \mathrm{M}$ & $\begin{array}{l}\text { Tabasco sauce, black pepper and } \\
\text { red pepper powder }\end{array}$ & 62 \\
\hline MWCNTs-MIPs GC & DPV & Capsaicin & $0.05-100 \mu \mathrm{M}$ & $0.02 \mu \mathrm{M}$ & Gutter oil & 49 \\
\hline Sn-rGO SPE & $\mathrm{CV}$ & Capsaicin & $0.2-22 \mu \mathrm{M}$ & $0.005 \mu \mathrm{M}$ & $\begin{array}{l}\text { Karen chili, bird's eye chili and } \\
\text { chili sauces }\end{array}$ & 52 \\
\hline GC & DPV & Capsaicin & $0.66-20.9 \mu \mathrm{M}$ & $0.198 \mu \mathrm{M}$ & Cubana red pepper & 72 \\
\hline $\mathrm{TiO}_{2} \mathrm{NP}$ GEC & $\mathrm{CV}$ & Capsaicin & $6-75 \mu \mathrm{M}$ & $5.34 \mu \mathrm{M}$ & $\begin{array}{l}\text { Delhuerto hot pepper sauce, } \\
\text { Tabasco habanero pepper sauce }\end{array}$ & 90 \\
\hline $\begin{array}{l}\mathrm{CeO}_{2} \text {-surfactant- } \\
\text { SWCNTs-GC }\end{array}$ & DPV & Capsaicin & $0.10-7.5 \mu \mathrm{M}$ & $28 \mathrm{nM}$ & Red hot pepper & 50 \\
\hline GrNPs ePAD & AdsSV & Capsaicin & $1-100 \mu \mathrm{M}$ & $0.37 \mu \mathrm{M}$ & Dried chile samples & 54 \\
\hline $\begin{array}{l}\text { Phospholipid } \\
\text { modified GC }\end{array}$ & ExSV & Capsaicin, dihydrocapsaicin & $\begin{array}{l}3-60 \mathrm{mg} \mathrm{L}^{-1} \\
9.3-60 \mathrm{mg} \mathrm{L}^{-1}\end{array}$ & $\begin{array}{l}2.1 \mathrm{mg} \mathrm{L}^{-1} \\
9.3 \mathrm{mg} \mathrm{L}^{-1}\end{array}$ & $\begin{array}{l}\text { Foxta, Madras Chilli, Habanero, } \\
\text { Carolina Reaper, bird's eye, Bhut } \\
\text { Jolokia, Naga Jolokia extract, } \\
\text { Habanero extract }\end{array}$ & 60 \\
\hline CD-ITO & $\mathrm{CV}$ & Capsaicin & $0.05-500 \mu \mathrm{M}$ & $5.4 \mathrm{nM}$ & $\begin{array}{l}\text { Cayenne pepper (powder), } \\
\text { Tabasco sauce, Thai chilli sauce }\end{array}$ & 57 \\
\hline
\end{tabular}

GC: glassy carbon; MECC-UV/EC: micellar electrokinetic capillary chromatography-UV and electrochemical detection; FI-EC: flow injectionelectrochemical detection HPLC-EC: high performance liquid chromatography-electrochemical detection; ND: not determined; *: simultaneous determination; 1: minimum detectible quantities (MDQ); BPPG: basal plane pyrolytic graphite electrode; AdsSV: adsorptive stripping voltammetry; CB: carbon black; GNP: graphene nanoplatelets; DPV: Differential pulse voltammetry; CV: cyclic voltammetry; SWV: square-wave voltammetry; PIGE: paraffinimpregnated graphite electrode; 2: method involves capsaicin micro-particles mechanically attached to the PIGE; 3: LOQ; HRP: horseradish peroxidase; NG: nanographite; SPEs: screen-printed electrodes; LSV: linear sweep voltammetry; NP: nanoparticle; CNTs; carbon nanotubes; PANI: polyaniline; MIPs: molecularly imprinted polymers; EDI: electrochemically driven intercalation process; BDD: boron-doped diamond; B2-CNT-SPEs: back-to-back carbon nanotube screen-printed electrodes; PGA: poly(gallic acid); IL: ionic liquid; PSS: poly(sodium 4-styrenesulfonate); Grp: graphite; rGO: reduced graphene oxide; GEC: graphite epoxy composite electrode; PDDA: poly dimethyl diallyl ammonium chloride; pHEMA: poly(2-hydroxyethyl methacrylate); ePAD: disposable electrochemical paper-based analytical device; GrNPs: N-doped graphene nanoplatelets; CD: carbon dots; ITO: indium tin oxide electrode; CPE: carbon paste electrode; $\mathrm{NH}_{2}$-FMS: amino-functionalized mesoporous silica; PAL: phenylalanine ammonia-lyase; CCSWV: coarse cyclic square-wave voltammetry; N-MC: nitrogen-doped mesoporous carbon; CD: cyclodextrins; ExSV: ex situ extractive stripping voltammetry. 
Flow injection analysis with direct and dual electrochemical detection

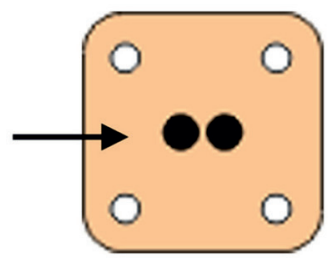

Simple pepper pungency determination in compliance with HPLC results
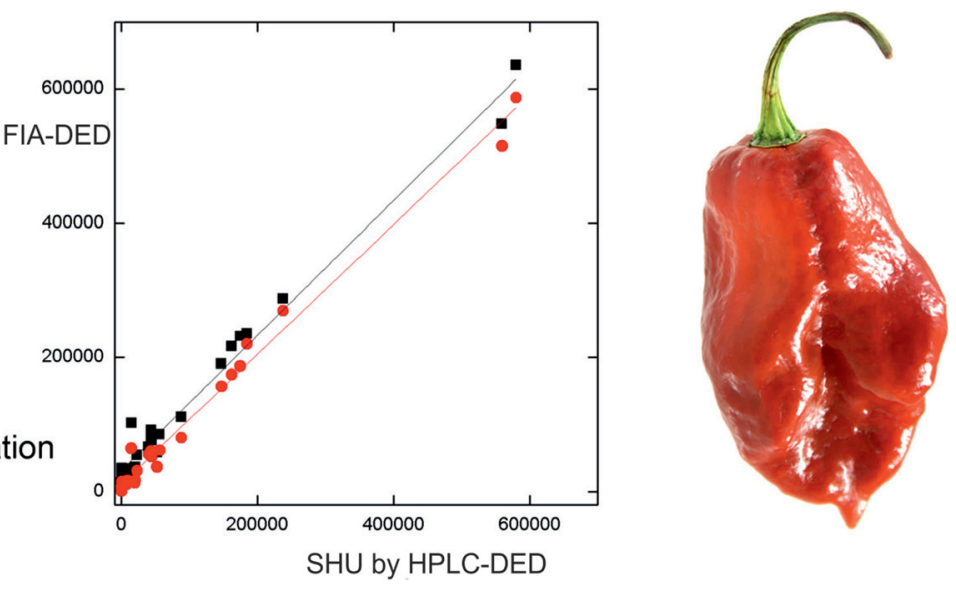

Fig. 1 (A) Schematic image of flow injection analysis with amperometric dual electrode detection using a thin layer cell with glassy carbon working electrodes. The correlation of SHU determined by HPLC-DED and by FIA-DED using E1 (upstream electrode, $E_{\mathrm{DET}}=1.0 \mathrm{~V}$; squares) and E2 (downstream electrode, $E_{\mathrm{DET}}=0.0 \mathrm{~V}$; circles) for electrochemical detection is also shown. ${ }^{39}$ Reproduced with permission from ref. 39 . Copyright Elsevier 2018.

\section{Electroanalytical approaches}

The first non-hyphenated technique was reported by Kachoosangi et $a l^{40}$ who explored the sensing of capsaicin using surface modified multi-walled carbon nanotube basal plane pyrolytic graphite electrodes (MWCNT-BPPGE). Fig. 2A shows the electrochemical oxidation of capsaicin, where the first voltammetric scan shows an initial sharp and welldefined peak (I) with a corresponding reduction peak (II) and upon the second scan, a new peak (III) appears while the initial peak (I) decreases. The proposed mechanism is also shown in Fig. 2B, where the electrochemical oxidation of capsaicin in the first scan is coupled to an irreversible homogeneous chemical step, which results in the hydrolysis of the 2-methoxy group to form an $o$-benzoquinone unit in the structure of capsaicin. ${ }^{40}$ The $o$-benzoquinone part of the capsaicin forms a redox electrochemical loop with catechol, which is observed as peaks II and III in the voltammetric profile presented in Fig. 2A. This electroanalytical methodology utilises adsorptive stripping voltammetry (AdsSV) where, prior to the voltammetric analysis, an accumulation step is applied and the capsaicin is adsorbed onto the MWCNTs surface. The authors opted for a MWCNT-BPPGE over a bare BPPGE due to adsorption being stronger on the former than on the latter due to the larger surface area. The MWCNT-BPPGE was applied to the sensing of capsaicin in real chilli sauce samples (Tabasco green pepper sauce, Tabasco pepper sauce, Tabasco habanero sauce, Da' Bomb Ground Zero, Blair's 2 AM Reserve and Mad Dog's Revenge). They employed a simple extraction technique where an aliquot of each chilli sauce was diluted with ethanol, placed in an ultrasonic bath for $10 \mathrm{~min}$, stirred for 2 hours using a magnetic stirrer and centrifuged at $10000 \mathrm{rpm}$ for 20 minutes to remove any solids. The supernatant liquid was then used for electrochemical analysis. Using a standard addition protocol, the chilli sauces were found to range from non-pungent to highly pungent with Mad Dog's Revenge having a SHU of 991700 . Unsurprisingly, this particular chilli sauce comes with a warning label on its bottle. 1 Fig. 2C shows the correlation between the chilli sauces measured in terms of electrochemically detected capsaicin and the average $\mathrm{SHU}^{40}$ using a conversion of $1 \mathrm{ppm}$ is equal to $15 \mathrm{SHU}$, though this should be more accurately 16 . The authors went further and demonstrated that this approach can be translated into a potential commercial sensor through utilising multi-walled carbon nanotube screen-printed electrodes (MWCNT-SPE) for the detection of capsaicin in standard and real samples. This paper suggested that electrochemical-based sensors have the potential to be utilized for the routine analysis of real samples within the food industry; indeed this is presented later in this review. More importantly, this paper provided the impetus for this sub-field of electroanalysis, which, as can be seen from Table 1, has rapidly expanded since this seminal paper was reported in 2008.

From this initial paper by Kachoosangi et $a .^{40}$ a plethora of electrochemical based approaches have been explored, (see Table 1) with many extending the observations of using carbon based materials to maximise the adsorption of capsaicin,

ๆThe Mad Dog's Revenge Chile Extract (Ashley Food Company) comes with the following warning label on its bottle: I agree, as indicated by my opening this bottle, as follows in connection with my purchase of this product. 1. Due to the extreme hot nature of this product, this product shall be used as a food additive. This product can cause serious injury if directly consumed, ingested or applied to the body. 2. Due to the extreme hot nature of this product, this product shall be used with extreme care in very small amounts. 3 . This product is to be used at my risk, and I fully understand the potential danger if used or handled improperly. 4. If I give this product as a gift, I will make the recipient fully aware of the potential danger if used or handled improperly. 5. I hereby disclaim, release and relinquish any and all claims, actions and lawsuits that I or any of my dependent heirs, family members or legal representatives, may have against any party relating to any damage or injury that may result, or is alleged to have resulted, from the use, consumption, ingestion, contact or other use of or from the product. 6. I am not inebriated or otherwise not of a sound mind, and I am fully able to make a sound decision about the purchase of this product. 


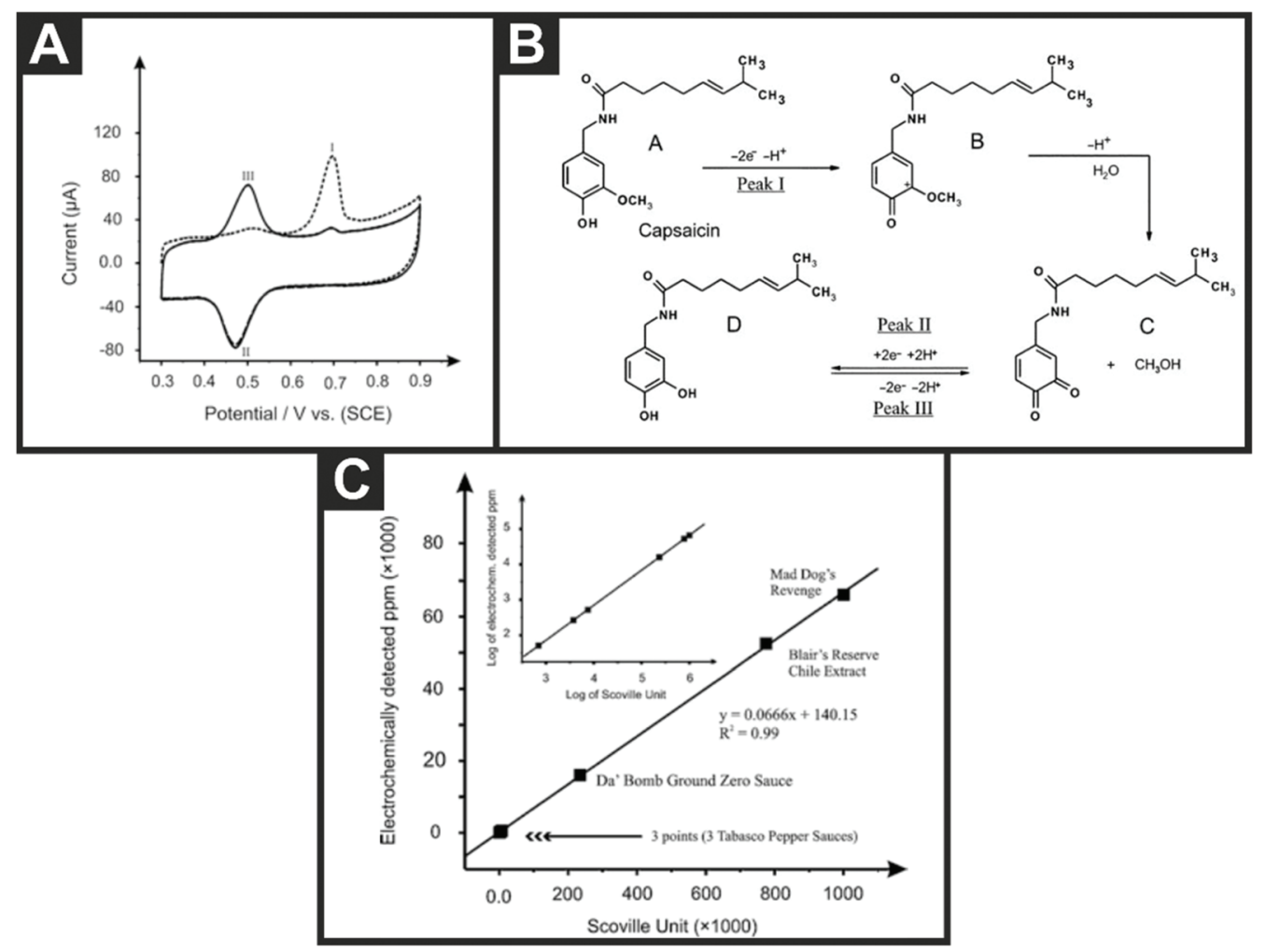

Fig. 2 (A) The first (dotted lines) and second (solid line) scans for the AdsSV of $100 \mu$ capsaicin on the MWCNT-BPPGE in a 0.05 M BrittonRobinson buffer solution at $\mathrm{pH}$ 1.0, after $1 \mathrm{~min}$ accumulation in open circuit conditions; scan rate: $100 \mathrm{mV} \mathrm{s}^{-1}$. (B) Proposed electrochemical mechanism for the electrochemical oxidation/reduction of capsaicin. (C) Measured value of capsaicin concentration in ppm (electrochemically detected $\mathrm{ppm}$ ) versus the average Scoville units for six hot pepper sauces. Inset: log of the electrochemically detected ppm versus log of the average Scoville units for six hot pepper sauces. Scheme and images reproduced with permission from ref. 40 . Copyright Royal Society of Chemistry $2008 .{ }^{40}$

using single-walled and multi-walled carbon nanotubes ${ }^{41-50}$ and, as new materials have been developed, reduced graphene oxide $^{51,52}$ and graphene $e^{53-55}$ in various composites. In the latter case, Kim et al. ${ }^{55}$ utilised graphene in a sol-gel with titania-Nafion ${ }^{\mathrm{TM}}$, producing a composite film modified glassy carbon electrode. The electroanalytical performances allowed the sensing of capsaicin from 0.03 to $10.0 \mu \mathrm{M}$ with a remarkably low detection limit of $8.6 \mathrm{nM}$. The authors attributed the low detection time to the target capsaicin molecules directly adsorbing onto the composite-modified GCE surface via $\pi-\pi$ interactions between capsaicin and graphene. The composite electrode was used to determine capsaicin in red chile pepper flakes and Chungyang chile peppers.

The electroanalytical determination of capsaicin using a BDD electrode in the presence of sodium dodecylsulfate (SDS) has also been explored. The electrochemical signals were not as strong as observed by others, which can obviously be understood due to the electrode characteristics, but useful analytical output was observed with a possible linear range from $0.16-20 \mu \mathrm{M}$ with a LOD found to correspond to $0.034 \mu \mathrm{M} .^{56}$ This approach was demonstrated to determine the concentration of capsaicin in Turkish hot (red) pepper paste and red pepper flakes. ${ }^{56}$ Randviir et $a l^{41}$ reported the use of screenprinted carbon single-walled and multi-walled nanotubes for the electroanalytical detection of capsaicin in both synthetic capsaicin solutions and capsaicin extracted from chiles and chilli sauces utilising both cyclic voltammetry (CV) and electrochemical impedance spectroscopy (EIS). The authors found that the choice of technique is largely concentration dependent: for the case of low capsaicin concentrations, SW-SPEs are the better choice with CV; and for high capsaicin concentrations MW-SPEs are the better choice for EIS. This has been explained through the use of linear calibration data, which exhibits high levels of linearity for peak height in the case of $\mathrm{CV}$ and charge transfer resistance in the case of EIS, with respect to concentration. The analytical performance of $\mathrm{CV}$ and EIS was applied to the sensing of capsaicin in chiles and chilli sauces and directly compared to HPLC-UV analysis. Following the theme of using carbon materials with high surface areas, another approach utilised by Xue et $a l^{57}$ was to utilise the high surface area of mesoporous cellular foams and they demonstrated that capsaicin could be determined in chile peppers, which was found to be in agreement with independent HPLC-UV. In a different approach, Ziyatdinova and coworkers ${ }^{48}$ have reported the use of a poly(gallic acid)-MWCNT modified glassy carbon electrode. The authors explored the electroanalytical detection of capsaicin, dihydrocapsaicin and nonivamide with detection limits of 2.9, 5.9 and $6.1 \mathrm{nM}$, respectively shown to be possible (measured separately). In comparison to a bare glassy carbon electrode, the poly(gallic 
acid)-MWCNT modified glassy carbon electrode exhibited improvements in electron transfer and analytical peak height. The selectivity of the capsaicinoids' quantification in the presence of ascorbic acid, $\alpha$-tocopherol and carotenoids is shown to be possible and the authors validated their electrochemical approach in red hot chile peppers successfully against HPLC. ${ }^{48}$ Another notable approach was reported by Supchocksoonthorn et al. ${ }^{57}$ who fabricated carbon dots synthesized from iota-carrageenan, which is an abundant food ingredient obtained from seaweed, using a one-step hydrothermal method, shown in Fig. 3A. The carbon dots, with an average diameter of $3.6 \mathrm{~nm}$, were grafted onto an indium tin oxide (ITO) substrate via a one-step thermal annealing process. This carbon dot-grafted ITO electrode was sensitive to capsaicin from 0.05 to $500 \mu \mathrm{M}$, with a low detection limit of $5.4 \mathrm{nM}$. Selectivity was demonstrated towards capsaicin in the presence of multiple interferences: $\mathrm{D}-(+)$-glucose, citric acid, L-ascorbic acid, $\mathrm{Na}^{+}, \mathrm{K}^{+}, \mathrm{Mg}^{2+}, \mathrm{Ca}^{2+}, \mathrm{Fe}^{2+}$ and $\mathrm{Cl}^{-}$. The authors validated their carbon dot-grafted ITO electrode towards capsaicin in Cayenne chile pepper, Tabasco sauce and a Thai chile, comparing directly with UV and HPLC-UV which yielded comparable results, providing independent verification that the electrochemical sensor can be used in practical applications, giving rise to accurate and meaningful pungency values. ${ }^{57}$ The authors reported that the electroanalytical platform could realise results within 5 minutes (excluding sample pre-treatment/extraction). Usefully, they also deduced the diffusion coefficient of capsaicin to be $1.56 \times 10^{-5} \mathrm{~cm}^{2} \mathrm{~s}^{-1}$ via the Wilke-Chang equation. ${ }^{58}$

The original mechanism for the electrochemical oxidation/ reduction of capsaicin was proposed by Kawada and coworkers, ${ }^{33}$ and later refined in detail by Kachoosangi et al. ${ }^{40}$ with only minor suggestions provided by Novak Jovanović and co-workers. ${ }^{59}$ These suggestions accounted for the different solution pHs used by experimentalists where the oxidation of the hydroxyl group in the capsaicin molecule occurs via different pathways, ${ }^{59}$ but essentially undergoes the same overall mechanism (EE mechanism). Jerga et al. ${ }^{60}$ explored the electrochemical oxidation of both capsaicin and dihydrocapsaicin using online electrochemical mass spectrometry with a coulometric cell connected to the MS equipped with an electrospray ionization (ESI) source. The authors reported the following reaction mechanism, as shown in Scheme 2. In this scheme, the electrochemical reaction initiates with the single electron and proton transfer from the phenolic hydroxyl group to form the phenoxyl radical 2 , which is stabilized by resonance. The conjugated radical 3 is further oxidized to cation $\mathbf{5}$ and hydrolysed to provide $o$-benzoquinone $\mathbf{6}$ and methanol. The reversible redox equilibrium between quinone 6 and catechol 7 is observed voltammetrically. ${ }^{60}$ Interestingly, another pathway was potentially observed, where the oxidation and subsequent hydrolysis of another resonance form $\mathbf{4}$ leads to methoxycatechol $\mathbf{9}$, which is further easily oxidized to the observed methoxybenzoquinone 10. ${ }^{60}$ We note that the logarithmic mass spectrometry signal intensity $v s$. applied potential indicates that at high overpotential, the main products are at $290 \mathrm{~m} / \mathrm{z}$ and $292 \mathrm{~m} / \mathrm{z}$ (rather than
$320 \mathrm{~m} / \mathrm{z}$ ) indicating that the main electrochemical reaction follows: 1, 2, 3, 5, 6, 7 (see Scheme 2). It is reassuring to see that online electrochemical mass spectrometry confirms earlier insights by Kachoosangi et al. ${ }^{40}$

Note that sample analysis is an important factor not to be overlooked. If you've ever eaten a chile pepper, you might have noticed that the second bite is hotter than the first. This is because the capsaicinoids are, as expected, not evenly distributed in the chile pepper. Some believe the seeds are the spiciest part, but it's actually the flesh near them that sets your tongue on fire. The part of the pepper closest to the stem is reported to be usually the hotter part because it has the highest concentration of capsaicin. This is anecdotal. True evidence, via analytical means, has reported that the highest capsaicin concentrations are found in the ovary (placenta) and in the lower flesh (apex) and the lowest capsaicin content can be found in seeds. ${ }^{61}$ In summary, clearly the whole chile needs to be sampled, indicating that the limiting step for in-the-field testing of chile peppers will be the sample preparation rather than the analytical methodology itself. Generally, it appears that researchers just adopt an extraction process ranging from simple extraction with solvents such as ethanol, using sonication $^{62}$ or manual shaking ${ }^{54}$ or reflux. ${ }^{63}$ Essentially the process is along those lines, with very little exploration of how this critical step will influence the final electroanalytical deduced SHU value. Interestingly, Lau and co-workers ${ }^{64}$ have utilised ionic liquids, which are broadly defined as liquids that comprise exclusively ions, have melting points of 100 degrees Celsius or lower and have been widely utilised as non-volatile, tuneable solvents that can be used as extractants. ${ }^{65}$ To that end, Lau et $a l .{ }^{64}$ explored the ability of ionic liquids to extract capsaicin from bird's eye chile peppers, reporting that the ionic liquids demonstrated superior extraction ability over that of the widely utilised ethanol extraction. ${ }^{64}$

Other approaches have explored the avenue of electrochemical biosensors for the determination of capsaicin, based on a signal amplification strategy using enzyme technology. As shown in Fig. 3B (ref. 45), a biosensor was constructed based on a platinum macroelectrode modified with multi-walled carbon nanotubes upon which Nafion ${ }^{\mathrm{TM}}$ and phenylalanine ammonia-lyase enzyme were added. The authors explored the role of the phenylalanine ammonia-lyase enzyme, observing that an 8-fold increase was possible using the enzyme, suggesting that this was the basis of the observed signal amplification strategy. The biosensor exhibited analytically useful parameters towards the sensing of capsaicin, comparable to other reported electrochemical based sensors (see Table 1). The effect of a range of interferents upon the determination of capsaicin was explored which confirmed the biosensor exhibited selectivity towards capsaicin determination. The authors explored the use of the biosensor for determining capsaicin in real chiles and found the amount of capsaicin to correlate with that recorded by HPLC, with density functional theory calculations suggesting that the interaction of the enzyme with the phenolic component of capsaicin is key to the improvement in terms of the biosensor's observed sensitivity. ${ }^{45}$ 


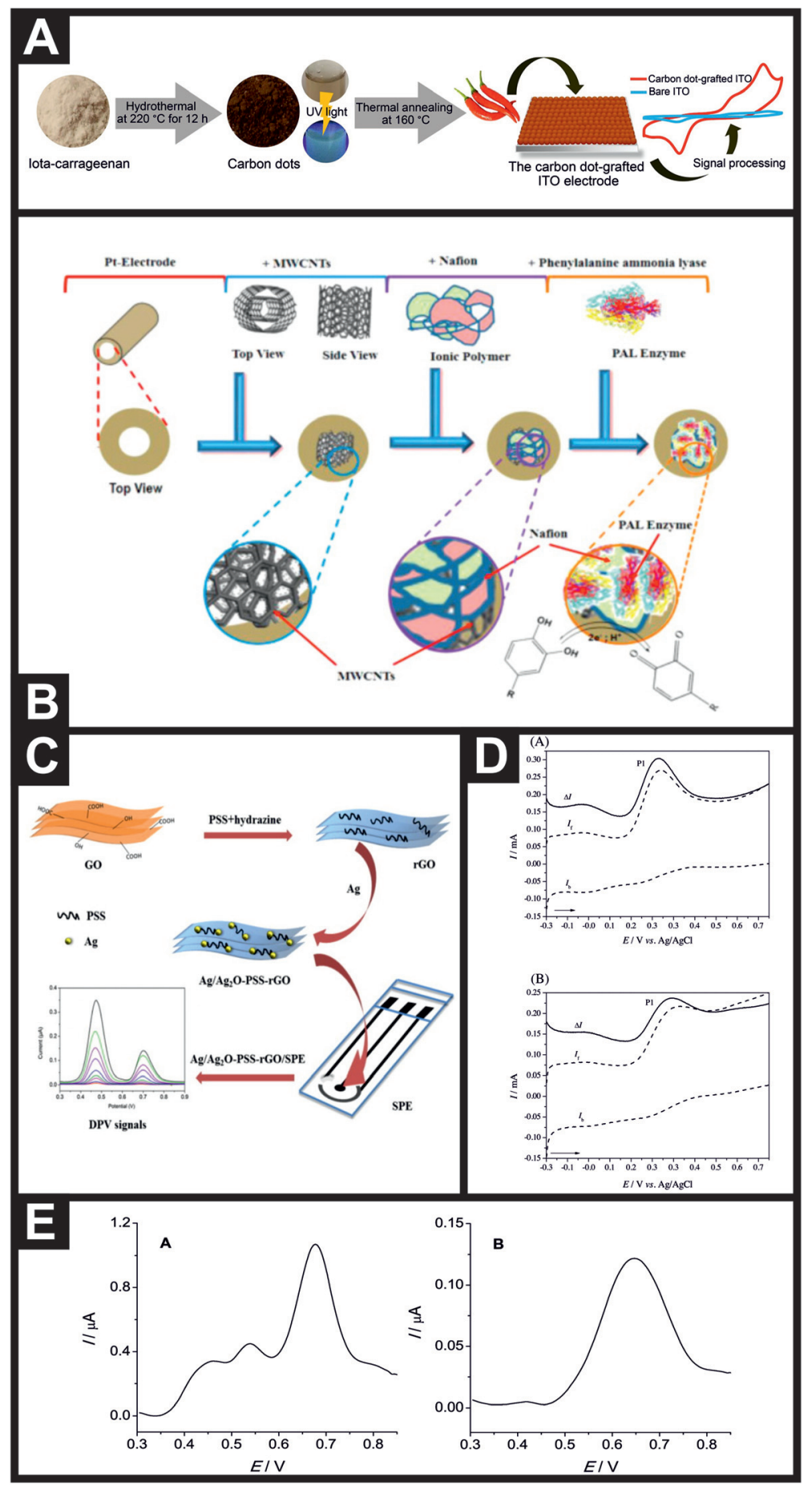

Fig. 3 (A) Schematic representation of the synthesis of carbon dots from iota-carrageenan, the grafting of carbon dots on ITO and capsaicin detection. ${ }^{57}$ Reproduced with permission from ref. 57. Copyright Elsevier 2021. (B) Electrochemical sensing platform using a platinum electrode modified with MWCNTs with phenylalanine ammonia-lyase enzyme immobilised using Nafion ${ }^{\mathrm{TM}}$ for the detection of capsaicin. ${ }^{45}$ Reproduced with permission from ref. 45. Copyright Elsevier 2016. (C) Overview of the fabrication of a $\mathrm{Ag} / \mathrm{Ag}_{2} \mathrm{O}-\mathrm{PSS}-\mathrm{rGO}$ composite and the measurement process of capsaicin. ${ }^{51}$ Reproduced with permission from ref. 51. Copyright Elsevier 2016. (D) Square-wave voltammetry of Bhut Jolokia (A) and Fatalli (B) microparticles immobilised on the surface of the PIGE and immersed in $0.1 \mathrm{M} \mathrm{KNO}_{3}, \mathrm{pH} 11 . \Delta /$ is the net response, $l_{\mathrm{f}}$ is the forward component and $l_{\mathrm{b}}$ is the backward component. ${ }^{59}$ Reproduced with permission from ref. 59. Copyright Elsevier 2016. (E) Direct differential pulse voltammetry: (A) using a polished glassy carbon electrode and ex situ extractive stripping differential pulse voltammetry, (B) using a phospholipid modified glassy carbon electrode, background subtracted. Sample: bird's eye chili pepper extract. ${ }^{60}$ Reproduced with permission from ref. 60. Copyright Elsevier 2020. 
<smiles>[R]C(=O)NCc1ccc(O)c(OC)c1</smiles>

capsaicin (CA):<smiles>[R]=CCCCC=CC(C)C</smiles>

dihydrocapsaicin (DHC):<smiles>[R][CH]CCCCCC(C)C</smiles><smiles>[R]C(=O)NCc1ccc([O-])c(OC)c1</smiles>

2

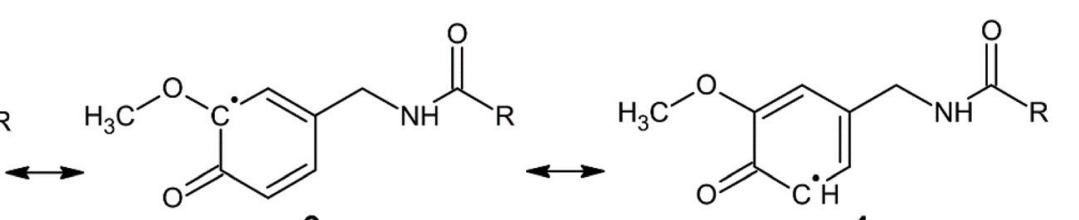<smiles>[R]C(=O)NCC1=C[C+](OC)C(=O)C=C1</smiles><smiles>[R]C(=O)NCC1=C[C+]C(=O)C(OC)=C1[Te]</smiles><smiles>[R]C(=O)NCC1=CC(=O)C(=O)C=C1</smiles>

$[\mathrm{M}+\mathrm{H}]^{+} 290 \mathrm{~m} / \mathrm{z}$

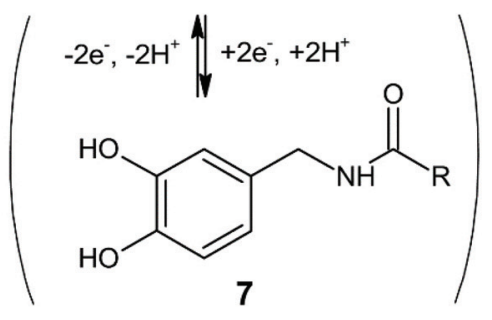

$[\mathrm{M}+\mathrm{H}]^{+} 292 \mathrm{~m} / \mathrm{z}$<smiles>[R]C(=O)NCc1cc(O)c(O)c(OC)c1[NH+](C)C</smiles><smiles>[R]C(=O)NCC1=CC(=O)C(=O)C(OC)=C1</smiles>

$[\mathrm{M}+\mathrm{H}]^{+} 320 \mathrm{~m} / \mathrm{z}$

Scheme 2 Mechanism of the electrochemical reactions of capsaicin and dihydrocapsaicin in acidic aqueous-methanolic media. Values of $m / z$ are indicated for protonated molecules of capsaicin and its reaction products detected in the ESI+ mode of the EC/MS experiment. Solution composition: $50 \mu \mathrm{M}$ for both capsaicin and dihydrocapsaicin in $0.6625 \mathrm{M} \mathrm{HCOOH}$ with $10 \%(\mathrm{v} / \mathrm{v})$ of $\mathrm{CH}_{3} \mathrm{OH}^{60}$ Reproduced with permission from ref. 60 . Copyright Elsevier 2020.

From an inspection of Table 1, other approaches to developing electrochemical sensors have utilised a range of nanomaterials, for example Wang and co-workers ${ }^{51}$ reported a $\mathrm{Ag} /$ $\mathrm{Ag}_{2} \mathrm{O}$-loaded poly(sodium 4-styrenesulfonate) (PSS) functionalized reduced graphene oxide ( $\mathrm{rGO}$ ) composite $\left(\mathrm{Ag} / \mathrm{Ag}_{2} \mathrm{O}-\mathrm{PSS}-\right.$ rGO) for the determination of capsaicin. Fig. 3C presents an overview of the fabrication approach, where GO is exfoliated by ultrasonication with hydrazine and PSS and thermally treated at 90 degrees for $3 \mathrm{~h}$, then washed, centrifuged and freezedried. Nanoparticle sized $\mathrm{Ag} / \mathrm{Ag}_{2} \mathrm{O}$ (4 nm diameter) were fabricated via a chemical reduction method and introduced through electrostatic interaction. This composite was electrically wired through the surface modification of SPEs where, using DPV, clear and well defined voltammetric signatures were observed (see Fig. 2). At pH 1.0, the nanocomposite electrode exhibited a linear range of 1-60 $\mu \mathrm{M}$ with a LOD of $0.4 \mu \mathrm{M}$ towards the sensing of capsaicin. ${ }^{51}$ The nanocomposite sensor was applied to the determination of capsaicin within red and green peppers and Capsicum frutescens via the standard addition method, which were found to have SHU of 616, 84 and 18422 respectively, corresponding to non-pungency through to moderately pungent. 
An interesting approach for capsaicinoid detection is the direct analysis of the microparticles of the sample, ${ }^{59}$ rather than the routinely applied solution phase detection which also requires sample pre-treatment (prior dissolution/extraction). Novak Jovanović and co-workers ${ }^{59}$ report the direct determination of the pungency of chile peppers in a solid sample by voltammetric analysis of immobilised microparticles. In this approach, the method simply involves taking an aliquot ( $\sim 2 \mathrm{mg}$ ) of the solid pepper sample, placing it onto a glazed ceramic tile, forming a spot of finely distributed material, and then abrasively transferring to the surface of a paraffin-impregnated graphite electrode via rubbing the electrode with a circular action. ${ }^{59}$ This approach was used to determine the pungency of nine hot (Bhut Jolokia, Red Savina, Fatalli, Habanero Orange, Carolina Cayenne, Cayenne, Jalapeño, Ancho and Hungarian wax) chile peppers, demonstrating a simple and rapid electrochemical method for the direct determination of hot peppers' pungency (see Fig. 3D for the sensor response to Bhut Jolokia and Fatalli chile peppers). Given the insights above that different parts of the chile pepper can give different SHU values, one hopes that the nine samples were indeed finely distributed ${ }^{59}$ and representative of the whole chile pepper.

In terms of real sample analysis, reports of the effect of interferents upon capsaicinoid detection and comparison to analytical standards (e.g. HPLC-UV) are severely lacking. A particular potential interferent, that is electroactive and a freshness indicator of foods such as chiles, is ascorbic acid. ${ }^{66}$ Ascorbic acid can easily be determined using carbon based electrodes but very few papers report the sensing of capsaicinoids and ascorbic acid. It has been reported that ascorbic acid is electrochemically inactive in the potential range commonly used for capsaicinoid determination. ${ }^{48}$ Most reports to date have not undertaken an interferent study ${ }^{45,49,52,62,67-70}$ and/or have not compared their electrochemical sensor to independent methods (such as HPLC-UV etc.). ${ }^{41,48,50,54,57,60,71-74}$ The effect of interferents in real samples is less of an issue in chilli foods such as sauces, where capsaicin levels are very high compared to other interfering species. However, for chile peppers the issue becomes more complex due to organic compounds being present; ${ }^{39,41,60,69}$ it is clear that real sample analyses are directed more to chilli products. If we explore the issue of ascorbic acid further, it has been reported that chile peppers are rich in ascorbic acid. ${ }^{75}$ The electrochemical oxidation of ascorbic acid is easily achievable at a range of carbon electrodes with the peak potential dependent upon the solution pH. ${ }^{76}$ Generally the analysis of capsaicin is undertaken at acidic ( $\mathrm{pH}$ 1.0) levels, where the voltammetric peak potential is also $\mathrm{pH}$ dependant. ${ }^{40}$ At this low $\mathrm{pH}$, the voltammetric waves of capsaicin and ascorbic acid should be resolved from each other, but of course both are dependent upon various factors, such as the electrode material; at insufficient resolution, peak broadening will occur which will hamper electrochemical analysis. We note that Moreno et al. ${ }^{72}$ have reported the electrochemical detection of capsaicin and ascorbic acid in
Cubana Red chile peppers using a glassy carbon electrode, using a simple extraction method, in which the results agree well with independent spectroscopic measurements. ${ }^{72}$ The authors noted that the electrochemical approach is cheap, simple and fast: 30 min $v s$. $\sim 2 \mathrm{~h}$ compared to the spectrophotometric method. ${ }^{72}$ Generally, authors successfully report the determination of capsaicin in real samples validated against HPLC-UV and other approaches mostly in chilli sauce type products; Tabasco sauce appears to be a favourite choice of the electroanalyst. It has also been shown that, in the case of determining capsaicinoids in chile peppers via electrochemical approaches, the results for chiles with low SHU levels do not agree well with independent methods, ${ }^{39,41}$ with better correlation observed at higher SHU levels where the ratio of capsaicinoids to interferents is in favour of the former. In addition, what is noticeable is that in real samples, both capsaicin and dihydrocapsaicin (with a ratio of 6:4) will be present but generally, the electrochemical sensor is not calibrated to both of them. This is because the oxidation peak potentials of capsaicin and dihydrocapsaicin are nearly identical, reported to be different by only $\sim 10 \mathrm{mV},{ }^{60}$ due to their very similar chemical structures. The total pungency of chile peppers and chilli products is a result of the combination of concentrations of both capsaicin and dihydrocapsaicin (current approaches assume these two chemicals produce the same level of pungency) and the voltammetric response in real samples will be a combination of both of them, thus if standard additions are undertaken, capsaicin is generally chosen to be used.

To overcome any issues of interferents in real chiles and chilli products, an interesting approach is the use of transfer voltammetry, ${ }^{69}$ where, after the accumulation step, the electrode is removed, rinsed with water and transferred to a new solution containing just the electrolyte. Further electrochemical analysis can then be conducted and ascorbic acid is left behind in the accumulation solution because of its poor adsorption ability on the chosen electrode surface. ${ }^{69}$ The authors noted that the process resulted in a peak that was about $50 \%$ of the height of the original voltammetric peak, but the sensitivity was still better than that when not undertaking the transfer voltammetry and removing the interferent that would have otherwise potentially hampered the electroanalytical determination. Another avenue is via the use of ex situ extractive stripping voltammetry. ${ }^{60}$ This approach uses a phospholipid modified glassy carbon electrode, which introduces selectivity into the sensing of capsaicinoids but obviously at the cost of sensitivity. In this novel approach, the hydrophobic phospholipid layer stops the transport of hydrophilic anions from the aqueous solution to the electrode surface. The analytical procedure involves the accumulation of capsaicinoids from the sample under investigation for a set period, after which, the electrode is rinsed with deionized water and placed into a new clean cell containing only the supporting electrolyte. To highlight the selectivity of the approach, the phospholipid modified glassy carbon electrode was compared to a bare/unmodified glassy carbon electrode. Fig. 3E 
shows the voltammetric profiles, using DPV for each electrode, obtained for a real chile pepper sample (bird's eye chile pepper). The voltammetric response using the bare/unmodified glassy carbon electrode shows two peaks, which are attributed to oxidisable, more polar interferents, which the authors suggest could be ascorbic acid and flavonoids. In contrast, the interferent peaks were absent using the phospholipid modified glassy carbon electrode with the ex situ extractive stripping voltammetry approach; the authors report that the latter is more selective to lipophilic capsaicinoids than the former. The authors measured the pungency of 8 chile samples (Foxta, Madras Chilli, Habanero, Carolina Reaper, bird's eye, Bhut Jolokia, Naga Jolokia extract, Habanero extract) using the bare/ unmodified glassy carbon electrode (direct DPV), the phospholipid modified glassy carbon electrode (with ex situ extraction DPV) and HPLC-UV. In the electrochemical approaches, both capsaicin and dihydrocapsaicin were measured to allow direct comparison with the HPLC-UV approach. It was observed that both electrochemical approaches under-estimated the pungency of the 8 chile samples in comparison to HPLC-UV. The authors noted that the best correlation was that of the phospholipid modified glassy carbon electrode (with ex situ extraction DPV) with HPLC-UV. ${ }^{60}$

\section{Translating from the laboratory to the field: the development of portable chile (and chilli) sensors}

Fig. 4A shows the first in-the-field prototype for measuring the pungency of chiles and chilli products produced by Oxford University, ${ }^{28}$ which is now sold and distributed as the ChilliPot. $^{30}$ Fig. 4B shows the device comprising disposable SPEs with a portable potentiostat connected via Bluetooth ${ }^{\circledR}$ to a smartphone running the associated software. In this approach, the pre-treatment of fresh, whole chile or dried pods involves a set mass being weighed out with buffer added, followed by blending to homogenise. A sample of this is taken to cover the three electrodes of the SPE. For very hot chiles, serial dilution is required. Another approach has extended the electrochemical detection of capsaicin reporting to a CMOS capsaicin concentration converter sensing chip, ${ }^{77}$ although it is yet to be applied for the determination of capsaicin in (real or model aqueous) samples.

Søpstad et al. ${ }^{78}$ developed a standalone electrochemical detection platform for capsaicin using unmodified screenprinted carbon graphite electrodes and an electrochemical technique known as coarsely stepped cyclic square wave voltammetry (CCSWV). Fig. 4C shows the standalone sensing platform where the material costs are around 25 euros. Note that the electrodes are non-detachable/disposable, unlike many other electrochemical based sensors. The reason for a preference for disposable electrodes is that a memory effect is observed and the electrode surface retains substances from the last measurement, resulting in falsely higher readings; to cir- cumvent this, SPEs are utilised to alleviate the need for polishing electrode surfaces. Søpstad et al. ${ }^{78}$ found that to overcome this issue and re-use the electrodes on their sensor, a solution of ethanol and buffer was used to remove any residual peaks from prior measurements. One downside is that the baseline signal becomes amplified which must be a result of surface changes; though not unambiguously defined by Søpstad et $a l . ;^{78}$ the authors report that this can be remedied through baseline signal subtraction. Another further consideration not reported on by Søpstad et al. ${ }^{78}$ is the longevity of the electrodes on the sensor, which are designed to not be removed, requiring the whole platform to be discarded. The authors validated their sensing platform for Tabasco Chipotle, Tabasco Pepper and Tabasco Habanero sauces. These real chilli sauces were diluted in a $1: 2$ ratio with ethanol and vortexed for $>1$ min to ensure good extraction efficiency, and centrifuged at 6000 RPM for 5 minutes. The supernatant was extracted and mixed with the buffer in a 1:9 ratio, leaving the final solution with a $1: 19$ ratio between sauce and buffer; ${ }^{78}$ clearly this is a sample pre-treatment obstacle to be overcome to realise a true in-thefield sensor. This approach has the benefit that it uses only one direct measurement (no standard addition protocol as utilised in other approaches ${ }^{40,56}$ ), simplifying the overall measurement protocol. We note that no independent analytical validation was undertaken to validate the proposed sensor. which clearly is a limitation. This proposed sensing platform has scope to be considered for other electrochemical sensing approaches, helping to bridge the gap between the laboratory and the field, but clearly has issues identified above which need to be overcome for it to be considered further as a potential in-the-field SHU sensor.

Another sensing platform of note is that by Soleh and coworkers $^{54}$ who utilised $\mathrm{N}$-doped graphene nanoplatelets to modify a disposable electrochemical paper-based analytical device (ePAD) and have fabricated a completely portable electrochemical sensor for capsaicin, termed the Chilica-Pod. Fig. 4D summarises the Chilica-Pod, which comprises a portable electrochemical device, in the shape of a small chile pepper, and contains a small potentiostat, a smartphone interface and a sensor that consists of the ePAD and a sample detection chamber, which has a filter layer (pore size: $0.1 \mathrm{~mm}$ ) to filter samples prior to measurement. The ePAD fabrication is achieved through the modification of chromatography paper, which is first printed with wax to create a hydrophobic barrier whereupon a three-electrode sensing configuration is screenprinted. Lastly, the SPEs are surface modified with N-doped graphene nanoplatelets and the electrodes are ready to use. While costs are given for each SPE sensor, no cost is given for the overall electrochemical sensing platform. The Chilica-Pod sensor $^{54}$ was shown to determine capsaicin in procured dried chile samples, which were weighted to a defined mass, to which $2 \mathrm{~mL}$ of buffer was added and manually shaken; 40 microliters of the sample was added to the sample detection chamber and the sample was rapidly analysed. The range of SHU values obtained from 6 chile samples ranged from non-pungent up to highly pungent, and the values were independently validated 


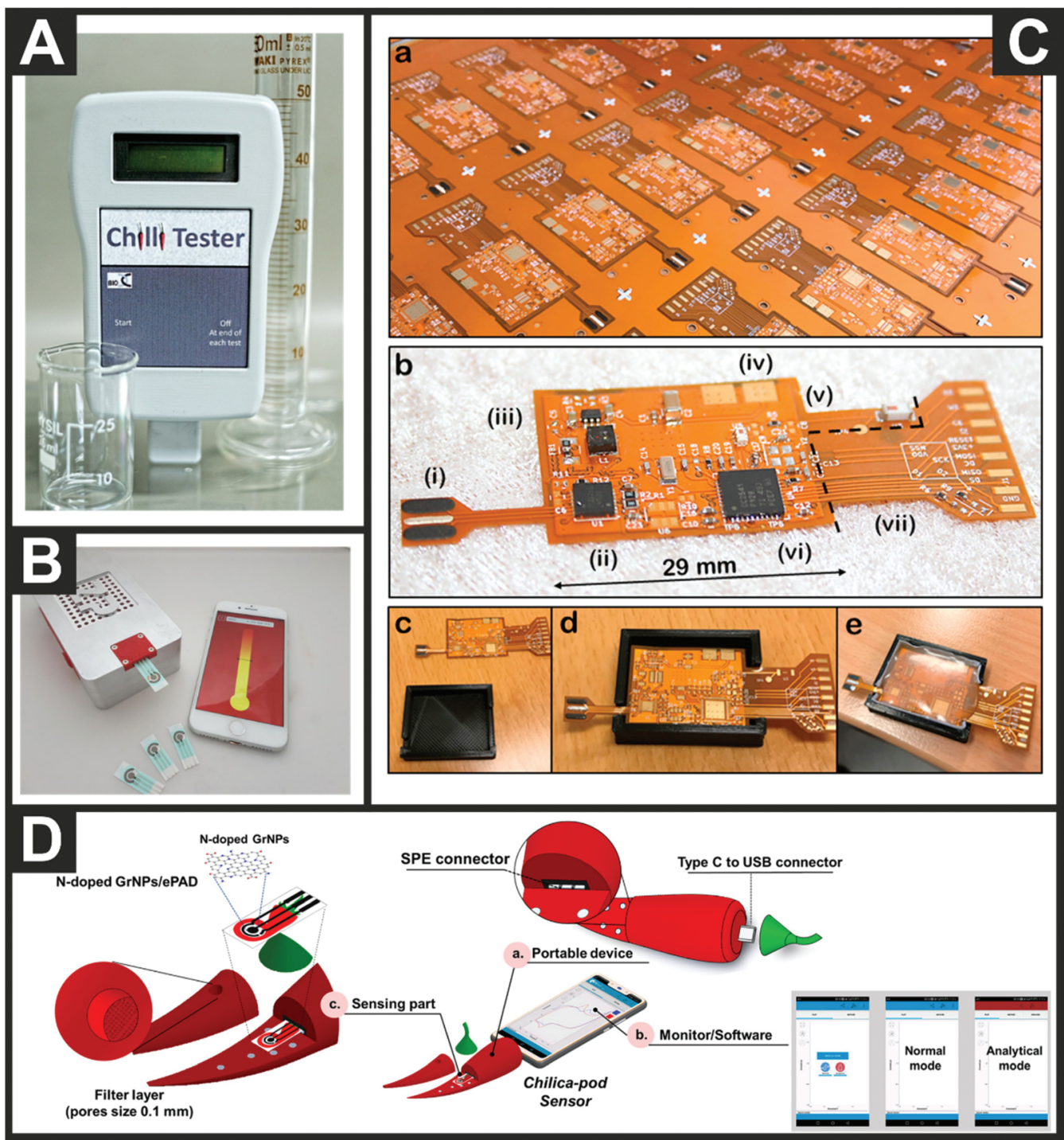

Fig. 4 (A) First in-the-field prototype for measuring the pungency of chiles and chilli products produced by Oxford University. ${ }^{28}$ (B) The commercial ChilliPot - the world's first Scoville Meter. ${ }^{30}$ (C) Photograph of the electrochemical sensor platform (a) on a $25 \times 25^{\prime \prime}$ panel before component assembly and (b) the single sensor platform after assembly. The Roman numerals indicate (i) the screen-printed electrodes, (ii) the chip potentiostat, (iii) the battery management circuitry, (iv) the terminals for the flexible battery (dimensions $29 \times 25 \times 0.6 \mathrm{~mm}$ ) situated on the backside, (v) the antenna circuitry for Bluetooth ${ }^{\circledR}$ Low Energy, (vi) microcontroller with an integrated analog-to-digital converter, and (vii) debug circuitry which can be cut off before deployment. (c-e) Photographs of the encapsulation of the electronic components in a 3D-printed mold. ${ }^{78}$ Reproduced with permission from ref. 78. Copyright Elsevier 2019. (D) Components of the Chilica-Pod portable electrochemical capsaicin sensor: (a) body of the portable electrochemical device, (b) monitor/software, and (c) sensor. ${ }^{54}$ Reproduced with permission from ref. 54 . Copyright American Chemical Society 2020.

with UV-vis spectrophotometry showing no significant difference between the two analytical approaches, suggesting that the Chilica-Pod sensor has real potential to provide rapid, accurate (not estimated) SHU values in real chile samples.

\section{Conclusions and outlook}

We have given an overview of the pursuit of capsaicinoid determination with emphasis upon electrochemical based sensing platforms, charting their first use in hyphenated techniques through to direct sensing, using advances in nanomaterials for the realisation of portable and cost-effective standalone sensing platforms. It is evident that electrochemical based sensors are indeed easy to use, with no need for highly skilled or experienced operators, and have a low cost and a high selectivity and sensitivity that make them an attractive approach to determine the pungency of chile peppers and chilli samples. While many electrochemical based sensors have been validated against gold standard analytical techniques (e.g. HPLC-UV) and shown to be successfully applied to real (chile/chilli) samples, others need to do the same when 
reporting new, potentially beneficial, electroanalytical sensors. We note that capsaicinoids are not only limited to foods but are also used in pharmacological products and medical applications; this could be a new avenue for the electrochemical methods reviewed in this paper to be directed to. The two major issues to be overcome are sample preparation and standardisation, and the development of techniques that are more selective; both are often overlooked and are needed to realise in-the-field electrochemical based pungency sensors.

\section{Conflicts of interest}

There are no conflicts to declare.

\section{References}

1 D. J. Bennett and G. W. Kirby, J. Chem. Soc. C, 1968, 442.

2 A. Garcés-Claver, M. S. Arnedo-Andrés, J. Abadía, R. GilOrtega and A. Álvarez-Fernández, J. Agric. Food Chem., 2006, 54, 9303-9311.

3 K. Kobata, T. Todo, S. Yazawa, K. Iwai and T. Watanabe, J. Agric. Food Chem., 1998, 46, 1695-1697.

4 P. H. J. Todd, M. G. Bensinger and T. Biftu, J. Food Sci., 1977, 42, 660-665.

5 M. G. Usman, M. Y. Rafii, M. R. Ismail, M. A. Malek and M. A. Latif, Molecules, 2014, 19, 6474-6488.

6 W. L. Scoville, J. Am. Pharm. Assoc., 1912, 1, 453-454.

7 D. P. Gmyrek, Pharm. Hist., 2013, 55, 136-156.

8 https://www.scovieawards.com/.

9 E. A. Weiss, Spice Crops, CABI Publishing International, New York, NY, USA, 2002.

10 H. Yang, Curr. Opin. Chem. Biol., 2012, 16, 422-428.

11 S. K. Boddhula, S. Boddhula, K. Gunasekaran and E. Bischof, BMJ Case Rep., 2018, 2018, DOI: 10.1136/bcr2017-224085.

12 M. N. Satyanarayana, Crit. Rev. Food Sci. Nutr., 2006, 46, 275-328.

13 A. M. Sánchez, M. G. Sánchez, S. Malagarie-Cazenave, N. Olea and I. Díaz-Laviada, Apoptosis, 2006, 11, 89-99.

14 V. Fattori, M. S. N. Hohmann, A. C. Rossaneis, F. A. PinhoRibeiro and W. A. Verri, Molecules, 2016, 21 (7), 844.

15 O. M. Hall, A. Broussard, T. Range, M. A. Carroll Turpin, S. Ellis, V. M. Lim, E. M. Cornett and A. D. Kaye, Curr. Pain Headache Rep., 2020, 24, 53.

16 D. E. Henderson, A. M. Slickman and S. K. Henderson, J. Agric. Food Chem., 1999, 47, 2563.

17 V. Cavett, E. M. Waninger, J. J. Krutak and B. A. Eckenrode, J. Forensic Sci., 2004, 49, 469-476.

18 H. H. Jang, J. Lee, S. H. Lee and Y. M. Lee, Sci. Rep., 2020, 10, 20912.

19 M. S. Westerterp-Plantenga, A. Smeets and M. P. Lejeune, Int. J. Obes., 2005, 29, 682-688.

20 M. D. L. Reyes-Escogido, E. G. Gonzalez-Mondragon and E. Vazquez-Tzompantzi, Molecules, 2011, 16, 1253-1270.
21 S. Zhang, D. Wang, J. Huang, Y. Hu and Y. Xu, J. Clin. Pharm. Ther., 2020, 45, 16-28.

22 N. O. Junior, V. Padulla, V. Ferraço and G. Ferronato, Use of Capsaicin for Nonlethal Technology, IntechOpen, UK, 2020.

23 W. D. Rollyson, C. A. Stover, K. C. Brown, H. E. Perry, C. D. Stevenson, C. A. McNees, J. G. Ball, M. A. Valentovic and P. Dasgupta, J. Controlled Release, 2014, 196, 96-105.

24 ASTA Method 21.3, Pungency of Capsicums and Their Oleoresins, 2004.

25 AOAC International, J. AOAC Int., 1998, 43, 43.

26 O. Sticher, F. Soldati and R. K. Joshi, J. Chromatogr. A, 1978, 166, 221-231.

27 J. E. Woodbury, J. - Assoc. Off. Anal. Chem., 1980, 63, 556558.

28 M. G. Usman, M. Y. Rafii, M. R. Ismail, M. A. Malek and M. A. Latif, Molecules, 2014, 19, 6474-6488.

29 A. M. Krajewska and J. J. Powers, J. Food Sci., 1988, 53, 902905.

30 A. Peña-Alvarez, E. Ramírez-Maya and L. Á. Alvarado-Suárez, J. Chromatogr. A, 2009, 1216, 2843-2847.

31 C. A. Reilly, D. J. Crouch, G. S. Yost and A. A. Fatah, J. Chromatogr. A, 2001, 912, 259-267.

32 A. da Silva Antonio, L. S. M. Wiedemann and V. F. da Veiga Junior, Food Anal. Methods, 2019, 12, 1327-1345.

33 T. Kawada, T. Watanabe, K. Katsura, H. Takami and K. Iwai, J. Chromatogr. A, 1985, 329, 99-105.

34 M. Y. Khaled, M. R. Anderson and H. M. McNair, J. Chromatogr. Sci., 1993, 31, 259-264.

35 S. Buratti, N. Pellegrini, O. V. Brenna and S. Mannino, J. Agric. Food Chem., 2001, 49, 5136-5141.

36 A. A. Kulkarni and I. S. Vaidya, J. Crit. Rev., 2015, 2, 19-24.

37 F. C. de Souza, D. A. I. da Silva, M. Simões, R. B. Faria, M. A. de Melo, R. M. Toledo and E. D'Elia, J. Appl. Electrochem., 2012, 42, 585-593.

38 S. M. D. Oliveira, A. Siguemura, H. O. Lima, F. C. D. Souza, A. A. O. Magalhães, R. M. Toledo and E. D'Elia, J. Braz. Chem. Soc., 2014, 25, 1399-1406.

39 H. Dejmkova, K. Morozova and M. Scampicchio, J. Electroanal. Chem., 2018, 821, 82-86.

40 R. T. Kachoosangi, G. G. Wildgoose and R. G. Compton, Analyst, 2008, 133, 888-895.

41 E. P. Randviir, J. P. Metters, J. Stainton and C. E. Banks, Analyst, 2013, 138, 2970-2981.

42 A. P. Ruas de Souza, M. Bertotti, C. W. Foster and C. E. Banks, Electroanalysis, 2015, 27, 2295-2301.

43 J. P. Metters, M. Gomez-Mingot, J. Iniesta, R. O. Kadara and C. E. Banks, Sens. Actuators, B, 2013, 177, 1043-1052.

44 T. Mpanza, M. I. Sabela, S. S. Mathenjwa, S. Kanchi and K. Bisetty, Anal. Lett., 2014, 47, 2813-2828.

45 M. I. Sabela, T. Mpanza, S. Kanchi, D. Sharma and K. Bisetty, Biosens. Bioelectron., 2016, 83, 45-53.

46 A. K. Baytak and M. Aslanoglu, Food Chem., 2017, 228, 152157.

47 K. Chaisiwamongkhol, C. Batchelor-McAuley, S. V. Sokolov, J. Holter, N. P. Young and R. G. Compton, Appl. Mater. Today, 2017, 7, 60-66. 
48 G. Ziyatdinova, E. Kozlova, H. Budnikov and R. Davletshin, Electroanalysis, 2019, 31, 222-230.

49 Mi Wang, B. Gao, Yu Xing and X. Xiong, Int. J. Electrochem. Sci., 2020, 15, 8437-8449.

50 G. Ziyatdinova, E. Ziganshina, A. Shamsevalieva and H. Budnikov, Arabian J. Chem., 2020, 13, 1624-1632.

51 Y. Wang, B. Huang, W. Dai, J. Ye and B. Xu, J. Electroanal. Chem., 2016, 776, 93-100.

52 W. Numphud, O. Chienthavorn and W. Siriwatcharapiboon, ScienceAsia, 2020, 46, 586-594.

53 D.-H. Kim, S. Nam, J. Kim and W.-Y. Lee, J. Electrochem. Sci. Technol., 2019, 10, 177-184.

54 A. Soleh, K. Saisahas, K. Promsuwan, P. Thavarungkul, P. Kanatharana and W. Limbut, ACS Appl. Nano Mater., 2020, 3, 10094-10104.

55 D.-H. Kim and W.-Y. Lee, J. Electroanal. Chem., 2016, 776, 74-81.

56 Y. Yardım, Electroanalysis, 2011, 23, 2491-2497.

57 Z. Xue, C. Hu, H. Rao, X. Wang, X. Zhou, X. Liu and X. Lu, Anal. Methods, 2015, 7, 1167-1174.

58 A. García-Miranda Ferrari, C. W. Foster, P. J. Kelly, D. A. C. Brownson and C. E. Banks, Biosensors, 2018, 8, 53.

59 I. Novak Jovanović, L. Čižmek and Š. Komorsky-Lovrić, Electrochim. Acta, 2016, 208, 273-281.

60 R. Jerga, A. Rajcová, V. Müllerová, P. Barták, P. Cankař, T. Navrátil and J. Skopalová, J. Electroanal. Chem., 2020, 858, 113790.

61 V. Supalkova, H. Stavelikova, S. Krizkova, V. Adam, A. Horna, L. Havel, P. Ryant, P. Babula and R. Kizek, Acta Chim. Slov., 2007, 54, 55-59.

62 P. B. Deroco, O. Fatibello-Filho, F. Arduini and D. Moscone, Electrochim. Acta, 2020, 354, 136628.

63 R. Mohammad, M. Ahmad and L. Y. Heng, Sens. Actuators, B, 2017, 241, 174-181.

64 B. B. Y. Lau, J. Panchompoo and L. Aldous, New J. Chem., 2015, 39, 860-867.

65 M. Freemantle, An Introduction to Ionic Liquids, The Royal Society of Chemistry, Cambridge, 2010.

66 K. Rekha and B. N. Murthy, Food Agric. Immunol., 2010, 21, 103-111.

67 F. Zhong, Z. Liu, Y. Han and Y. Guo, Electroanalysis, 2019, 31, 1182-1188.

68 P. Temcheon, O. Chienthavorn, W. Siriwatcharapiboon and P. Hasin, Microporous Mesoporous Mater., 2019, 278, 327339.

69 Y. Yardım and Z. Şentürk, Talanta, 2013, 112, 11-19.

70 W. Lyu, X. Zhang, Z. Zhang, X. Chen, Y. Zhou, H. Chen, H. Wang and M. Ding, Sens. Actuators, B, 2019, 288, 65-70.
71 E. D. de León Zavala, L. M. T. Rodríguez, A. Montes-Rojas, V. H. T. Mendoza and A. E. L. González, J. Electroanal. Chem., 2018, 814, 174-183.

72 M. T. Moreno, R. E. Brito, M. Córdoba and M. R. M. José, J. Chem. Res., 2021, 111-115, DOI: 10.1177/ 1747519820930965.

73 Z. Xue, C. Hu, H. Rao, X. Wang, X. Zhou, X. Liu and X. Lu, Anal. Methods, 2015, 7, 1167-1174.

74 R. Mohammad, M. Ahmad and L. Y. Heng, Sensors, 2013, 13, 10014-10026.

75 A. K. Owk and S. T. Sape, Not. Sci. Biol., 2009, 1, 50-52.

76 F. Wantz, C. E. Banks and R. G. Compton, Electroanalysis, 2005, 17, 1529-1533.

77 C. T. Chiang, F. C. Hsu, W. J. Lin and J. C. Chen, presented in part at the 2020 IEEE International Conference on Mechatronics and Automation (ICMA), 13-16 Oct. 2020, 2020.

78 S. Søpstad, K. Imenes and E. A. Johannessen, Biosens. Bioelectron., 2019, 130, 374-381.

79 H. Watanabe, K. Murakami, H. Imazawa and J.-M. Kauffmann, Electroanalysis, 2017, 29, 1513-1517.

80 K. Morozova, I. Rodríguez-Buenfil, C. López-Domínguez, M. Ramírez-Sucre, D. Ballabio and M. Scampicchio, Electroanalysis, 2019, 31, 844-850.

81 Y. Ya, L. Mo, T. Wang, Y. Fan, J. Liao, Z. Chen, K. S. Manoj, F. Fang, C. Li and J. Liang, Colloids Surf., B, 2012, 95, 90-95.

82 G. K. Ziyatdinova and H. C. Budnikov, J. Anal. Chem., 2014, 69, 990-997.

83 S. Wu, J. Zeng, H. Xie and S. H. Ng, Anal. Methods, 2016, 8, 7025-7029.

84 V. Maksimova, V. Mirceski, R. Gulaboski, L. K. Gudeva and Z. A. Sarafinovska, Int. J. Electrochem. Sci., 2016, 11, 66736687.

85 Y. Wang, B.-B. Huang, W.-L. Dai, B. Xu, T.-L. Wu, J.-P. Ye and J.-S. Ye, Anal. Sci., 2017, 33, 793-799.

86 L. M. T. Rodríguez, F. G. R. Torres, N. E. G. Orta and J. F. R. Martínez, Synth. Met., 2017, 223, 153-165.

87 R. Sukanya, M. Sakthivel, S.-M. Chen, T.-W. Chen, F. M. A. Al-Hemaid, M. Ajmal Ali and M. S. Elshikh, Microchim. Acta, 2018, 185, 313.

88 G. D. Pierini, C. W. Foster, S. J. Rowley-Neale, H. Fernández and C. E. Banks, Analyst, 2018, 143, 3360-3365.

89 H. Naskar, B. Ghatak, S. Biswas, B. Tudu, R. Bandyopadhay and P. Pramanik, 2019 IEEE International Symposium on Olfaction and Electronic Nose (ISOEN), 2019, pp. 1-3, DOI: DOI: 10.1109/ISOEN.2019.8823183.

90 M. Sarma and M. del Valle, Electroanalysis, 2020, 32, 230-237. 